\title{
Integration of fire protection of farmland, steppe and forest tracts with agrotechnical processes of their treatment with the help of airships
}

\author{
Valery Belozerov ${ }^{1, *}$, Alexey Denisov ${ }^{2}$, and Mikhail Nikulin ${ }^{3}$ \\ ${ }^{1}$ Don State Technical University, Gagarina sq. 1, Rostov-on-Don, 344003, Russia \\ ${ }^{2}$ Academy of the State Fire Service, B.Galushkina str, 4, Moscow, 129366, Russia \\ ${ }^{3}$ State Agricultural University of the Northern Trans-Urals, Republic str., 7, Tyumen, 625003, Russia
}

\begin{abstract}
The article presents the results of a system analysis of the use of unmanned aerial vehicles (UAVs), including for agricultural technologies, as well as airplanes and helicopters for fighting fires. Based on the results of the analysis, a systemic synthesis of a hybrid aircraft was carried out to integrate the solution of these problems, which is the airship. It is shown that airships are mobile, reliable and autonomous means, with a high carrying capacity and weight return, versatility of use and low total cost: 10 times less than the manufacture of a helicopter and 100 times lower than its operating costs. At the same time, unlike UAVs, airships allow the use of nanotechnology (membrane, thermomagnetic) separation of atmospheric gases as an "endless source of fire extinguishing composition" to suppress ignitions and landscape fires, and also solve all UAV tasks, including innovations in agricultural technologies.
\end{abstract}

\section{Introduction}

Unmanned aerial vehicles (UAVs) are beginning to be used in various fields of human activity, and obviously the time has come for their use in the largest industry - agriculture.

Already in 2016, about $48 \%$ of commercial UAVs were used in the field of agriculture, and according to foreign forecasts, by 2026 this figure will grow to $80 \%$. For example, in Pittsburgh (USA), Skycision actively uses UAVs and infrared technologies, both in the diagnosis of diseases and for monitoring pests of agricultural crops. The UAV operator takes hundreds and thousands of infrared images and then creates a detailed map with photos. Moreover, infrared sensors are even able to determine the amount of chlorophyll in plants, which is a marker of diseases - if chlorophyll is reduced, the crops are affected. In this case, you can use the "Doctor of plant medicine" program, which will diagnose the problem and give a recommendation for the processing of agricultural crops [1].

In China, for example, UAVs help Chinese farmers spray weeds and carry out work. with the aim of increasing yields, and the lack of labor in rural areas creates a demand for such services. Today, Shenzhen-based DJI already controls about $70 \%$ of the global

\footnotetext{
* Corresponding author: safeting@,mail.ru
} 
commercial UAV market, positioning its Agras MG-1 and Mavic 2 drones as industrial, and this segment accounts for more than half of the global UAV market (total value: \$ 9 billion) .... And in the Indian state of Maharashtra, since the end of last year, UAVs have been actively used to create maps and irrigate farmland with their help. Also in India, flying laboratories are being developed as part of WeRobotics. Farmers learn to predict harvests, take timely action at an early stage in the spread of disease, remotely probe, calculate plot sizes, classify crop types, map, plan harvesting, or pest control (fig.1 "a" and "b") [1].

Currently, monitoring of agricultural lands, as well as forests and steppe areas is carried out using helicopters, airplanes, satellites and even a simple bypass of fields with measuring instruments, which takes a lot of time and resources. Thanks to the UAVs, this can be done much faster and cheaper. Equipping UAVs, for example, with ultrasonic "scarers", can protect fields from birds and rodents, and spraying the appropriate chemicals from other crop pests. The use of infrared cameras and other innovations simplifies and accelerates the transition to precision farming $[1,2]$.

An alternative solution was the use of motor hang-gliders, equipped with special equipment, which made it possible to get rid of the problems of "big aviation" and to reach a new level of quality of farmland processing. So, for example, the agrochemical complex (ACC) "Agropatrul-04", developed by specialists of LLC "AVIASPEKTR", has been operating in the Samara region since the end of the last century and has established itself as a reliable and economical ACC, which can work from almost any dirt road and limited sites ... The installed chemical equipment allows you to add drugs with maximum accuracy. The tests carried out by specialists from the Krasnodar Institute for the Application of Aviation in the National Economy confirmed the high quality of the work of the ACC [3].

In Russia, for eight years now, on the basis of Moscow Engineering Physics Institute, they have been engaged in UAVs for various applications on a single platform that allows monitoring the environment, video filming and cargo transportation. However, each complex was manufactured individually, and such a system was poorly scalable, and in order to produce data understandable to a farmer, a lot of work was required, which is beyond the power of one company. Therefore, AgroDronGroup is a group in which there are two laboratories at Moscow State University, the Research Institute of Agrochemistry Pryanishnikov, the Research Institute of Potato Growing Lorkh, the Research Institute of Biological Plant Protection and even the Korean University of Konkuk, i.e. a group that brings together experts in the agricultural sector and UAV specialists. With the help of such a combination, field experiments are carried out, which lead to the formation of algorithms for the formation of databases, with the use of which we obtain data that the farmer understands. At the same time, the cost of supplying a UAVs depends on several parameters: the volume of areas and the volume of analytics, since for one type of analytics it is necessary to make one overflight, and for another type - five overflies, including the factor of the distance of the farm from the bases with the UAVs [2]. 


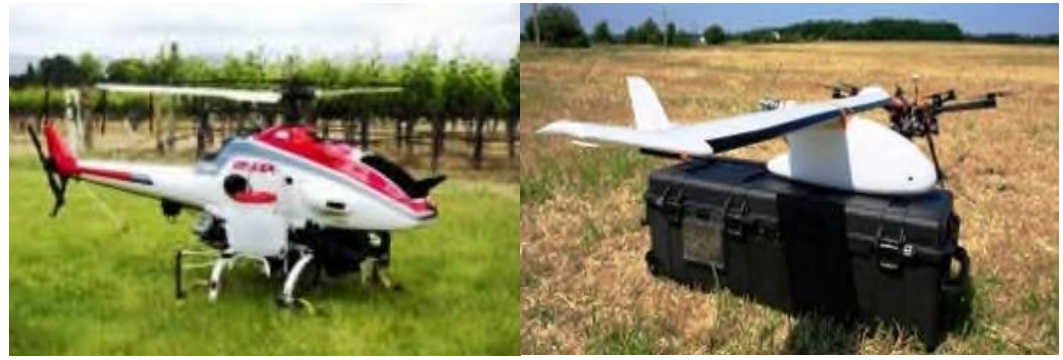

a)

b)

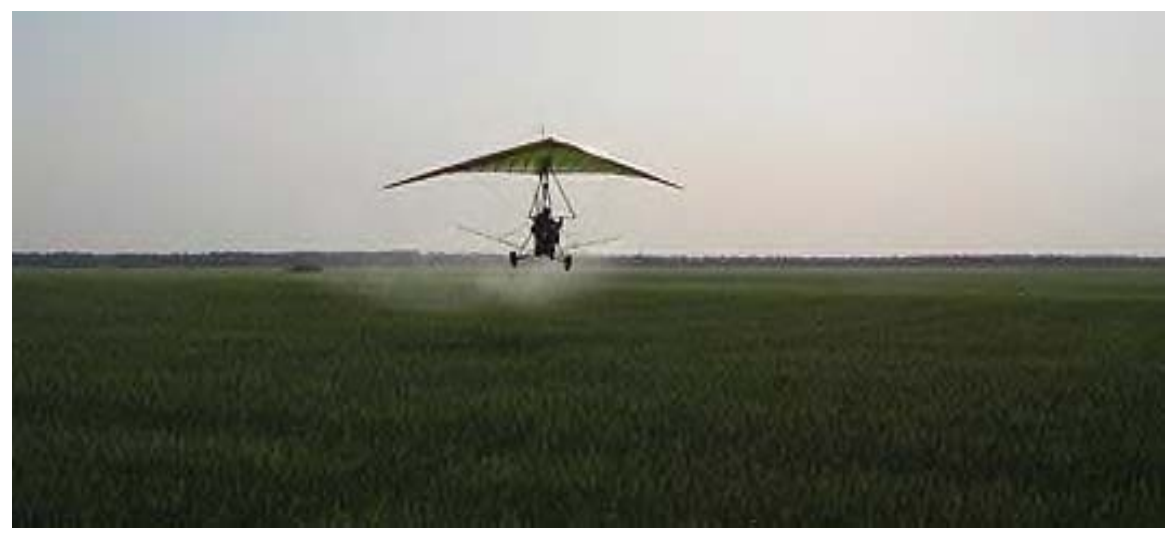

c)

Fig. 1. UAVs ("a" and "b") and motor hang-glider ("c"), Source: http://www.aviaspektr.ru/

Monitoring with the help of UAVs of farmland and forest areas can economically solve the problems of early detection of fires, the main causes of which are the type of dominant vegetation, climatic conditions and the "human factor" [4-5].

The fact is that the real scale of forest fires in Russia and the amount of damage caused by fire have not been reliably established to date, since regular monitoring of forest fires is carried out only in the zone of active protection of forests, due to the limited material and human resources [5-6].

Many countries, such as the USA, Canada, Australia, France, for which the problem of forest fires is urgent, have special aviation fire brigades, and Russia is no exception, because fire fighting equipment based on aircraft in Russia has been used for almost 90 years: test flights to monitor the fire situation have been carried out on two-seat biplane U-2 (PO-2) since 1931 [7].

For example, AN - 32P with a full refueling of two tanks with a total capacity of 8 tons at a speed of $240-260 \mathrm{~km} / \mathrm{h}$, spraying the composition at a height of $40-50 \mathrm{~m}$, allows you to create a protective strip up to $160 \mathrm{~m}$ long and up to $35 \mathrm{~m}$ wide. effectively extinguishing a fire using the BE-200 aircraft, which in the planing mode fills its 6-ton tanks with water in 14-16 seconds, including on a wave height of up to 0.8 meters. The aircraft is very economical - for one refueling, it is able to collect and bring down 320 tons of water to the fire. However, the disadvantage of these methods and devices is a very significant complexity of aerobatics, as well as the fact that there are not always reservoirs near the fires that allow water intake in the planing mode [7-8].

Unlike airplanes, helicopters MI-8, Ka-32 and MI-26 with spillways (APU), the transport speed of a container with water is much lower and in case of fires in small areas or in mountainous areas, this is a fundamental advantage, since plums at high speeds, at heights exceeding 40-50 m from the earth's surface, the discharged liquid as a result of the 
incoming air flow breaks down to the state of aerosols and most of it evaporates before reaching the fire source [8].

A common disadvantage of these methods and devices is the high cost of both the equipment itself and its operation, as well as low efficiency, since airplanes and helicopters constantly have to refuel with water, fly up to the fire site, pour out water and fly away to refueling, during which the fire flares up with renewed vigor $[8,9]$.

Recently, both in Russia [10,11] and abroad, a new class of hybrid aircraft has appeared, combining the principles of an airship, an airplane and a helicopter: in Russia - BARS and DELTOSKAN, in the USA - P-791, in England - Skyship. In China, the French company Flying Whales, together with the Chinese state aircraft company General Aircraft Co., Ltd, are building a plant for LCA60T rigid airships with a carrying capacity of 60 tons, filled with helium, the serial production of which is scheduled for 2021 [12].

Thus, airships are mobile, reliable and autonomous means, with a high carrying capacity and weight efficiency, versatility of application, up to the solution of manned space missions [13] and a low total cost, including the manufacturing cost - 10 times lower than helicopters, and operating costs - 100 times lower. However, all these aircraft (airplanes, helicopters, airships) use water to extinguish fires, which, as a rule, is not available in the steppe and forest areas [7-13].

\section{Results and discussion}

A system analysis of the above agrotechnical problems and tasks of protecting farmland, steppe and forest areas leads to the conclusion that it is possible and necessary to integrate them with the help of airships, incl. and in unmanned modes, using nanotechnology (membrane, thermomagnetic) separation of atmospheric gases, as an "endless source of fire extinguishing composition", to suppress fires in mountainous areas, forest and landscape fires, as well as the above innovations for UAVs and agricultural technologies $[14,15]$.

In contrast to the configuration of the airship according to the claimed method of detecting and extinguishing farmland, steppe and forest fires with atmospheric nitrogen [15], a nitrogen membrane station (NMS) container can be the "1st floor" of a rigid suspension complex, which, due to its weight and size characteristics (dimensions - $6.0 \times$ $2.5 \times 3.6 \mathrm{~m}$, weight $-11,500 \mathrm{~kg}$ ) may well replace the necessary "mooring devices", and on the "2nd floor" a pilot's cabin and other necessary compartments can be mounted (Fig.2), for the implementation of technological and auxiliary functions.

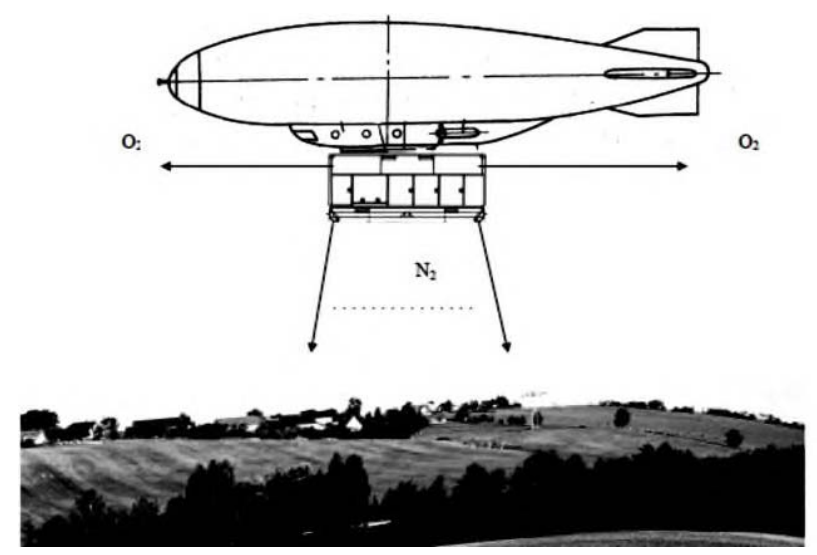

Fig. 2. Diagram of the model with NMS 
The results of the system synthesis of models for the integration of agrotechnical and fire-fighting tasks have shown their high efficiency [4,14-15]:

firstly, due to the possibility of equipping airships with any equipment for diagnosing the environment and underlying surface, which cannot be installed on a UAV, and is difficult to adapt to onboard versions for helicopters and airplanes,

secondly, because of the possibility of a convenient (without parachute) "landing" of agricultural specialists and / or firefighters-rescuers with the necessary technical means anywhere on the patrol route of the airship, which is impossible not only for UAVs, but also for aircrafts, as well as for all helicopters, except for MI-26,

thirdly, because of the economy of movement and the simplicity of "hovering and landing" of the airship as needed when patrolling along the route, including watering, spraying fertilizers and of protection chemicals,

fourth, in the absence of duplication and the possibility of economically creating and maintaining in real time a unified database of farmland, steppe and forest areas,

fifthly, in the possibility of round-the-clock patrolling and response to emergencies along the optimal routes of the territories of all regions of Russia, including remote and mountainous areas, which is impossible neither by existing means, nor by UAVs, nor by individual by services (Ministry of Emergency Situations, Rosles, Agroprom) due to the limited material and human resources,

sixth, they do not require the construction of special "berthing facilities"

seventh, in the emergence of the effect of synergistics that ensures fire safety and food security.

According to the calculations of the specialists of the Russian Aeronautical Society, the flying hour of the airship costs about 4 thousand rubles, i.e. almost 3 orders of magnitude cheaper than a helicopter (on average 40 thousand rubles). Moreover, if the average density of the cargo is less than $0.4 \mathrm{t} / \mathrm{cu}$. $\mathrm{m}$, then transporting them by airships is more economical than by airplanes, and at a density of less than $0.2 \mathrm{t} / \mathrm{cu}$. $\mathrm{m}$ - more economical than any land means of transport [15].

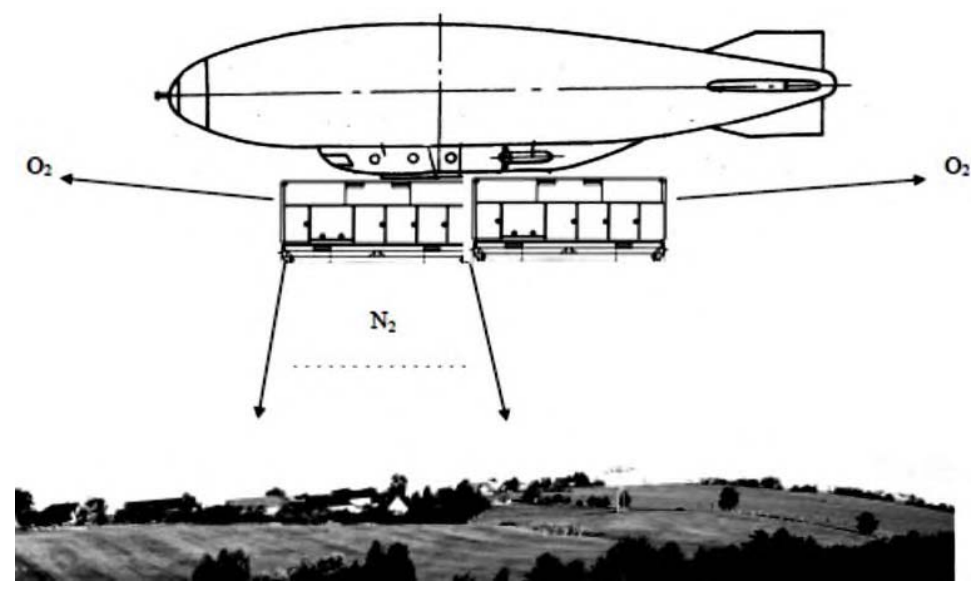

Fig. 3. Diagram of a model with AMU and an additional container for equipment and/or "landing"

If, to perform agrotechnical or rescue tasks, it is necessary to transport water for irrigation or solutions for spraying, fertilizers or equipment, then the obvious solution is to dock the AMU container with a similar container for these purposes (Fig. 3), without increasing operating costs (within the carrying capacity airship). 


\section{Conclusions}

Thus, in terms of carrying capacity and spaciousness, the airship surpasses all today's means of aviation forest protection and means leased by the agro-industrial complex, in connection with which it can be argued that the combination of solving the problems of ensuring safety and agricultural technology will reduce the unit costs for each of the them, because the airship, due to the aerostatic scheme, has constant costs for its movement, independent of the load (within the limits of its carrying capacity)

Moreover, the proposed integration of the tasks performed by the airship's crew and its technological capabilities make it possible to protect against the spread of fires in the steppes and forests by installing "electric protective strips" instead of mineralized ones. Domestic studies of the effect of electric and acoustic fields on the processes of combustion and extinguishing fires dating back to the end of the last century have shown their high efficiency. In particular, it was found that high-voltage pulsed electric fields emitted by a metal mesh (Fig. 4) block the spread of fire much more efficiently than mineralized strips, and also do not require equipment for embankment [16].

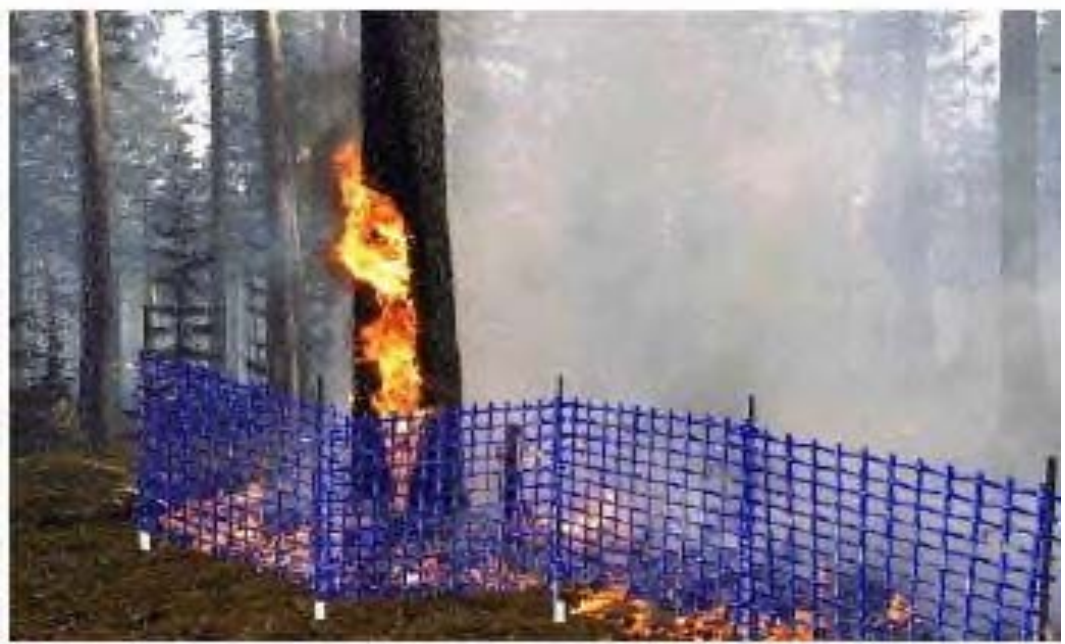

Fig. 4. Tests of electrical fire protection mesh

\section{Reference}

1. F. Veroustraete, EC Agriculture 2.2, 325-327 (2015)

2. V. Gautam, S. Sarkar, Proceedings of UASG $2019 \quad 415-424 \quad$ (2020) https://doi.org/10.1007/978-3-030-37393-1_34

3. V. Karasev, A. Karaseva, Patent RU 2465174 (2012)

4. N. Topolsky, V. Belozerov, N. Afanasyev, Technologies of technosphere safety 4, 6-12 (2010)

5. G. Ivanova, and et al., Environmental Research Letters 6 (2011) https://doi.org/10.1088/1748-9326/6/4/045203

6. E. Kukavskaya and et al., Environmental Research Letters 8 (2013) https://doi.org/10.1088/1748-9326/8/4/045034.

7. V. Perminov and et al., Fire protection in the service of the state 1918-2018 92-130 (2018) 
8. F. Kurakov, The Economics of Science 3(3), 214-226 (2017) https://doi.org/10.22394/2410-132X-2017-3-3-214-226

9. A. Simonis, Y. Gonze, E. Bargeton, Patent US10343760B2 (2017)

10. S. Nikulin, N. Popov, A. Shanin, Patent RU 2573489 (2016)

11. S. Belokon and et al., Autometry 55-4, 37-48 (2019) https://doi.org/10.15372/AUT20190404

12. I. Kulikov, Manned space flights 4, 92-105 (2019) https://doi.org/10.34131/MSF.19.4.92-105

13. Global strategic framework for food security and nutrition, CFS 2012/39/5 1(1), 1-39 (2012).

14. V. Belozerov, M. Nikulin, N. Topolsky, Nanotechnology for the suppression of fires in agricultural land and forests E3S Web of Conferences 175, 12007 (2020) https://doi.org/10.1051/e3sconf/202017512007 .

15. A. Basharichev, M. Maslakov, Bulletin S-Pb USFS EMERCOM of Russia 3, 43-46 (2015) 